This article is licensed under the Creative Commons Attribution-NonCommercial 4.0 International License (CC BY-NC) (http://www.karger.com/Services/OpenAccessLicense). Usage and distribution for commercial purposes requires written permission.

\title{
Long-Term Progression of Sensorineural Hearing Loss and Tinnitus after Combined Intensity-Modulated Radiation Therapy and Cisplatin-Based Chemotherapy for Nasopharyngeal Carcinoma: A Case Report
}

\author{
Ming S. Lee Sudha Penumala $^{a} \quad$ Steven Sweet $^{b} \quad$ Russell R. De Luca $^{c}$ \\ Ariel E. Stearnes ${ }^{a} \quad Y^{2}$ amac Akgun ${ }^{a}$ \\ ${ }^{a}$ Trinity School of Medicine, Kingstown, Saint Vincent and the Grenadines; \\ ${ }^{b}$ Interventional Radiology, Baltimore Washington Medical Center, Glen Burnie, MD, USA; \\ ${ }^{c}$ Chesapeake Oncology and Hematology Associates, Glen Burnie, MD, USA
}

\section{Keywords}

Nasopharyngeal carcinoma · Cisplatin-based chemotherapy · Intensity-modulated radiotherapy $\cdot$ Sensorineural hearing loss $\cdot$ Tinnitus

\section{Abstract}

Sensorineural hearing loss (SNHL) is a common adverse effect for nasopharyngeal carcinoma (NPC) patients treated with chemoradiotherapy. We report a case of 12-year follow-up from a patient with stage IIB NPC, treated in 2004 with intensity-modulated radiotherapy and cisplatin-based chemotherapy. Pure-tone audiograms were conducted before treatment and at two other points in the 12-year period after treatment. Analysis of the patient's audiograms reveals that the development of high-frequency SNHL started after treatment and reached a 


\section{Case Reports in Oncology}

Case Rep Oncol 2017;10:743-751

DOI: $10.1159 / 00047884$

(C) 2017 The Author(s). Published by S. Karger AG, Base www.karger.com/cro

Lee et al.: Long-Term Progression of SNHL and Tinnitus after Combined

Intensity-Modulated Radiation Therapy and Cisplatin-Based Chemotherapy for NPC

plateau accompanied by tinnitus approximately 32 months after treatment conclusion. After the plateau, high-frequency SNHL continued to develop slowly in the next 10 years, possibly a long-term effect from radiation-induced microvascular change of the hearing apparatus. The continuous high-frequency hearing decline is associated with increased tinnitus pitch in the patient. With experience learned from this case, we recommend hearing tests at regular intervals for at least 3-5 years for NPC patients treated with chemoradiotherapy. Patients need to be educated about tinnitus and counseling can be offered when they begin to feel inconvenienced by tinnitus. These patients also need to be advised against exposure to noise that can aggravate the already compromised hearing apparatus, leading to further hearing loss and worsening tinnitus. Limiting the peak dose and total cumulative dose of cisplatin should be considered based on the patients' risk factors to achieve a balance between treatment efficacy and long-term adverse effects.

(C) 2017 The Author(s)

Published by S. Karger AG, Basel

\section{Introduction}

Nasopharyngeal carcinoma (NPC) is a rare type of malignancy most often found in certain parts of Asia and North Africa. The highest incidence is in southern China and in areas of Southeast Asia that historically incorporated immigrants from the endemic areas in China [1]. In the United States, increased incidence of NPC among African-American teenagers has been noted [2]. NPC is known to be multifactorial in etiology. Genetic susceptibility, exposure to carcinogens, and prior infection with Epstein-Barr virus (EBV) are known risk factors for developing NPC [1]. Intensity-modulated radiation therapy (IMRT) combined with cisplatin-based chemotherapy has been established as the standard of care for various stages of NPC [1]. In recent years, intensity-modulated proton therapy has been shown to be superior to IMRT in its ability to spare vital tissues [3]. However, IMRT is relevant in current practice as the availability of intensity-modulated proton therapy is still limited [4]. With increased cure rate and survival time, minimizing adverse effects from treatment is becoming a major concern for NPC patients. A better understanding of the adverse effect progression through time can facilitate the development of effective monitoring strategies and preventive measures to help the patients cope with unavoidable consequences from treatment.

Sensorineural hearing loss (SNHL) is a common treatment adverse effect for NPC patients. SNHL after NPC treatment is thought to be a result of damage to the cochlear hair cells incurred by radiation and cisplatin-based chemotherapy [5]. SNHL can be categorized into low-frequency and high-frequency types. Low-frequency SNHL is usually assessed with hearing at frequency thresholds of $500,1,000$, and 2,000 Hz and high-frequency hearing loss with thresholds greater than $4,000 \mathrm{~Hz}[5,6]$. The high-frequency type is more common and tinnitus often develops in patients who suffer from high-frequency SNHL [7]. Because NPC has a bimodal age distribution with the lower age group peaking at early adulthood (15-24 years) [8], young survivors have to deal with treatment adverse effects for decades of life expectancy. Thus, the issue of long-term progression of SNHL is especially important to the quality of life of NPC patients.

Findings in the current literature suggest that persistent high-frequency SNHL is common after NPC treatment, and combining cisplatin-based chemotherapy with radiotherapy 


\section{Case Reports in Oncology}

increases the incidence and severity of SNHL $[5,6,9]$. However, the existing literature is inconclusive on the nature of long-term progression of SNHL after chemoradiotherapy. It was reported that high-frequency SNHL can occur any time after the initiation of NPC treatment with occurrence probability reaching the plateau between 18 and 24 months after treatment [6]. One study suggested that treatment-induced SNHL can continue to increase with time [9]. It is noted that some of the early studies on SNHL after NPC treatment were based on short follow-up time [5]. In addition, existing studies had not addressed the progression and consequences of SNHL at frequencies higher than 4,000 $\mathrm{Hz}[5,6,9]$.

We report a case of a 12-year follow-up from a patient with stage IIB NPC, treated in 2004 with IMRT and cisplatin-based chemotherapy. Hearing tests were conducted before treatment and at two other points in the 12-year period after treatment. This case report presents a time series of SNHL progression and tinnitus development that has not been presented before in the existing literature.

\section{Case Report}

The patient is an Asian-American male with ancestry from southern China. At the age of 35 in 2004, he presented with persistent right-sided nasal congestion that could not be relieved with antibiotics and corticosteroid nasal sprays. Four months after the initial presentation, a mass appeared on the right side of his neck, and subsequent workup confirmed the diagnosis of poorly differentiated, nonkeratinizing squamous cell carcinoma of the nasopharynx, staged IIB, T2a N1 M0 [10]. CT images of the primary tumor and cervical nodal involvement are shown in Fig. 1 and Fig. 2. The patient has a family history of NPC in his paternal grandmother. Retrospective serum analysis performed in 2017 revealed that the patient had been infected with EBV. His antibody IgG to EBV nuclear antigen was $503 \mathrm{U} / \mathrm{mL}$ and his IgG to EBV viral capsid antigen was $541 \mathrm{U} / \mathrm{mL}$. Both readings greatly exceed the positive threshold at $21.9 \mathrm{U} / \mathrm{mL}$.

The patient completed a course of chemoradiotherapy consisting of IMRT with a total dose of 70 Gy in 30 fractions and 8 cycles of cisplatin-based chemotherapy. The chemotherapy protocol included 3 cycles of cisplatin $100 \mathrm{mg} / \mathrm{m}^{2}$ concurrent with radiation and 5 cycles of adjuvant chemotherapy with cisplatin $80 \mathrm{mg} / \mathrm{m}^{2}$ plus fluorouracil (5-FU) $1,000 \mathrm{mg} / \mathrm{m}^{2}$. He received $700 \mathrm{mg} / \mathrm{m}^{2}$ of the total cumulative dose of cisplatin. The treatment process was uncomplicated. He did not develop secretory otitis media during treatment. After treatment, there has been no recurrence or metastasis. He also has no history of hypertension, diabetes, or other chronic conditions that can cause hearing loss.

The patient's treatment adverse effect profile includes hypothyroidism, residual neuropathy of the hands and feet, and bilateral tonal tinnitus that occurred in 2007, approximately 36 months after completion of IMRT and 32 months after the last cycle of adjuvant cisplatin administration. The tinnitus onset was sudden without prodrome and triggered an extended period of frequent anxiety episodes in the patient. He describes his tinnitus as constant high-pitch ringing sensation of approximately equal intensity in both ears. Except for the tinnitus, he has not experienced noticeable hearing changes in his activities of daily living. However, he reports that the ringing sensation of his tinnitus seems to be running in a higher pitch in the last few years than before. 


\section{Case Reports in Oncology}

Case Rep Oncol 2017;10:743-751

DOI: $10.1159 / 000478847$

(C) 2017 The Author(s). Published by S. Karger AG, Basel www.karger.com/cro

Lee et al.: Long-Term Progression of SNHL and Tinnitus after Combined

Intensity-Modulated Radiation Therapy and Cisplatin-Based Chemotherapy for NPC

Three weeks before initiating IMRT, a hearing test including pure-tone audiometry, tympanometry, and speech discrimination was conducted to establish the baseline hearing of the patient. Immediately after the onset of tinnitus, two hearing tests separated by 3 months were conducted to assess the level of hearing loss and to verify if hearing loss was still progressing. The two tests yielded identical results, suggesting that SNHL had likely reached the plateaus at the time. For the next 10 years, no hearing test was done as the patient had not noticed any change in hearing. At a follow-up exam 12 years after treatment in 2017, the patient agreed to have a hearing test to assess long-term progression of hearing loss. Results of the serial hearing tests showed normal tympanometry and speech discrimination before and after treatment. The series of air conduction thresholds are summarized in Fig. 3. It is noted that, although the patient's audiogram shows sloping at 6,000 and $8,000 \mathrm{~Hz}$ before treatment in 2004 (see Fig. 3), his hearing thresholds at these frequencies were within normal limits of males in their 30s with normal hearing [11]. Thus, the patient was not hearing-impaired before treatment and the threshold increases after treatment can be reasonably attributed to the adverse effects of chemoradiotherapy. Table 1 summarizes the threshold increases between hearing tests.

\section{Discussion}

According to the American Speech-Language-Hearing Association, clinically relevant SNHL is defined as an increase in hearing threshold for more than $15 \mathrm{~dB}$ at two or more contiguous frequencies [12]. Table 1 shows that at the onset of tinnitus, the patient had increased hearing thresholds across all frequencies. The increases at low frequencies (250$3,000 \mathrm{~Hz}$ ) are in the range of 5-10 dB, which are considered normal clinically [12]. Consistent with findings from past studies, after treatment, the patient demonstrated clinically relevant high-frequency SNHL with both ears exhibiting threshold increase greater than or equal to $15 \mathrm{~dB}$ at $4,000,6,000$, and $8,000 \mathrm{~Hz}$. Moderate SNHL of greater than $30 \mathrm{~dB}$ is observed at $6,000 \mathrm{~Hz}$ for both ears and at $8,000 \mathrm{~Hz}$ for the left ear.

For the 10 years past the onset of tinnitus (2007-2017), no further increase in lowfrequency thresholds is observed. Interestingly, there is slight improvement in hearing at frequencies 250, 500, and 1,000 Hz. At the high frequencies (400-8,000 Hz), threshold increase is observed in the range of 5-15 dB. It is important to note that hearing loss through normal aging is expected from 2007 to 2017 as the patient aged from his 30s to 40s. Thus, to find out hearing loss that may be attributed to the long-term effect after NPC treatment, the patient's threshold increases from 2007 to 2017 need to account for expected normal agerelated hearing loss. Table 2 summarizes the hearing threshold levels of otologically normal males in their 30s and 40s, based on data from the European Committee for Standardization [11]. For a normal male aging from his 30 s to 40 s, we can expect that $90 \%$ of them have hearing threshold increases of at least 9, 10, and $11 \mathrm{~dB}$ at 4,000, 6,000, and 8,000 Hz, respectively. Comparing the values in Tables 1 and 2, the patient's threshold increase at 4,000 $\mathrm{Hz}$ (5 dB) from 2007 to 2017 is within the range of hearing loss expected for normal aging $(9 \mathrm{~dB})$. However, his threshold increases at $6,000 \mathrm{~Hz}$ for the left ear and $8,000 \mathrm{~Hz}$ for the right ear are both $15 \mathrm{~dB}$, marginally exceeding the levels expected for normal age-related hearing loss. 


\section{Case Reports in Oncology}

Case Rep Oncol 2017;10:743-751

DOI: $10.1159 / 000478847$

(C)

(C) 2017 The Author(s). Published by S. Karger AG, Base www.karger.com/cro

Lee et al:: Long-Term Progression of SNHL and Tinnitus after Combined

Intensity-Modulated Radiation Therapy and Cisplatin-Based Chemotherapy for NPC

It was found that in some patients the pitch of tinnitus correlates with the edge frequency and the steepest downward slope of the audiogram [13]. The edge frequency is the frequency at which hearing loss worsens abruptly, creating a steep slope on the audiogram corresponding to abrupt discontinuities in the activity along the tonotopic axis of the auditory system. The discontinuities can be misinterpreted as sound and perceived by the patient as the ringing pitch of tinnitus. For our patient, at the onset of tinnitus, the edge frequency is in the vicinity of $4,000 \mathrm{~Hz}$ and the steepest slope occurs somewhere between 4,000 and $6,000 \mathrm{~Hz}$ (see Fig. 1). It appears that the high-frequency SNHL in our patient had been continuously progressing after NPC treatment, resulting in an audiogram steep slope correlated with tinnitus onset approximately 32 months after treatment conclusion. In the 10 years after tinnitus onset, low-frequency SNHL in our patient had stabilized, but high-frequency SNHL appeared to have slowly progressed. By 2017, the patient's audiogram slope between 4,000 and $6,000 \mathrm{~Hz}$ has become steeper than it was in 2007. The deepening of the slope can potentially shift the edge frequency and the tonotopic axis discontinuities to a higher frequency, which may explain the patient's experience that his tinnitus pitch has become higher in recent years.

In summary, the development of high-frequency SNHL in our patient started after treatment and reached a plateau approximately 32 months after the last cycle of cisplatin administration. The plateau at 32 months is longer than previously reported at 24 months [6]. A previous study reported that increasing cumulative cisplatin dose (median, 400 $\mathrm{mg} / \mathrm{m}^{2}$; range, $200-800 \mathrm{mg} / \mathrm{m}^{2}$ ) was significantly related to hearing loss at high frequencies [14]. We suspect that the extended progression time to plateau in our patient may be a result of cisplatin at a total cumulative dose of $700 \mathrm{mg} / \mathrm{m}^{2}$, which is higher than the doses received by patients in the study that rendered 24-month plateau. After the plateaus, SNHL continued to progress slowly in our patient at high frequencies, exceeding the level expected for normal age-related hearing loss. It was reported that microvascular changes of the hearing apparatus after radiation therapy can have such long-term effect [15]. With the experience learned from this patient, we recommend hearing tests at regular intervals for at least 3-5 years for NPC patients treated with chemoradiotherapy. Patients need to be educated about SNHL and tinnitus and counseling can be offered when they begin to feel inconvenienced by the tinnitus. These patients also need to be advised against exposure to noise that can aggravate the already compromised hearing apparatus, leading to further hearing loss and worsening tinnitus. Finally, limiting the peak dose and total cumulative dose of cisplatin should be considered based on the patients' risk factors as excessive cisplatin dose can have significant impact on the long-term progression and SNHL and tinnitus for the patients.

\section{Statement of Ethics}

The authors have no ethical conflicts to declare.

\section{Disclosure Statement}

The authors have no conflicts of interest to disclose. 


\section{Case Reports in Oncology}

Case Rep Oncol 2017;10:743-751

DOI: $10.1159 / 00047884$

(C) 2017 The Author(s). Published by S. Karger AG, Base www.karger.com/cro

Lee et al: Long-Term Progression of SNHL and Tinnitus after Combined

Intensity-Modulated Radiation Therapy and Cisplatin-Based Chemotherapy for NPC

\section{References}

1 Van Waes C, Haglund KE, Conley BA: Head and neck cancer; in Abraham J, Gulley JL, Allegra CJ (eds): Bethesda Handbook of Clinical Oncology, ed 4. Philadelphia, Lippincott Williams \& Wilkins, 2014, pp 1-29.

2 Chu EA, Wu JM, Tunkel DE, Ishman SL: Nasopharyngeal carcinoma: the role of the Epstein-Barr virus. Medscape J Med 2008;10:165.

-3 van Dijk LV, Steenbakkers RJ, ten Haken B, et al: Robust intensity modulated proton therapy (IMPT) increases estimated clinical benefit in head and neck cancer patients. PLoS One 2016;11:e0152477.

$4 \quad$ National Association for Proton Therapy Supporting Members: National Association for Proton Therapy Web site. http://www.proton-therapy.org/members_section.html. Updated 2017. Accessed June 9, 2017.

-5 Wang J, Chen Y-Y, Tai A, et al: Sensorineural hearing loss after combined intensity modulated radiation therapy and cisplatin-based chemotherapy for nasopharyngeal carcinoma. Transl Oncol 2015;8: 456-462.

-6 Chan SH, Ng WT, Kam KL, et al: Sensorineural hearing loss after treatment of nasopharyngeal carcinoma: a longitudinal analysis. Int J Radiat Oncol Biol Phys 2009;73:1335-1342. Kim DK, Park SN, Kim HM, et al: Prevalence and significance of high-frequency hearing loss in subjectively normal-hearing patients with tinnitus. Ann Otol Rhinol Laryngol 2011;120:523-528. Bray F, Haugen M, Moger TA, Tretli S, Aalen 00, Grotmol T: Age-incidence curves of nasopharyngeal carcinoma worldwide: bimodality in low-risk populations and aetiologic implications. Cancer Epidemiol Biomarkers Prev 2008;17:2356-2365.

Hwang C-F, Fang F-M, Zhuo M-Y, Yang C-H, Yang L-N, Hsieh H-S: Hearing assessment after treatment of nasopharyngeal carcinoma with CRT and IMRT techniques. Biomed Res Int 2015;2015:769806. American Joint Committee on Cancer: AJCC Cancer Staging Manual 6th Edition. 2002. European Committee for Standardization (CEN): Acoustics Statistical distribution of hearing thresholds as a function of age. ISO 7029:2000, 2000. Type, degree, and configuration of hearing loss. American speech-language-hearing association. Website http://www.asha.org/uploadedFiles/AIS-Hearing-Loss-Types-Degree-Configuration.pdf. Published 2015. Accessed June 8, 2017.

13 König 0, Schaette R, Kempter R, Gross M: Course of hearing loss and occurrence of tinnitus. Hear Res 2006;221:59-64.

14 Frisina RD, Wheeler HE, Fossa SD, Kerns SL, Fung C, Sesso HD, et al: Comprehensive audiometric analysis of hearing impairment and tinnitus after cisplatin-based chemotherapy in survivors of adultonset cancer. J Clin Oncol 2016;34:2712-2720.

15 Carlson ML, Jacob JT, Pollock BE, et al: Long-term hearing outcomes following stereotactic radiosurgery for vestibular schwannoma: patterns of hearing loss and variables influencing audiometric decline. J Neurosurg 2013;118:579-587. 


\section{Case Reports in Oncology}

\begin{tabular}{l|l} 
DOI: $10.1159 / 000478847$ & C 2017 The Author(s). Published by S. Karger AG, Basel
\end{tabular} www.karger.com/cro

Lee et al: Long-Term Progression of SNHL and Tinnitus after Combined

Intensity-Modulated Radiation Therapy and Cisplatin-Based Chemotherapy for NPC

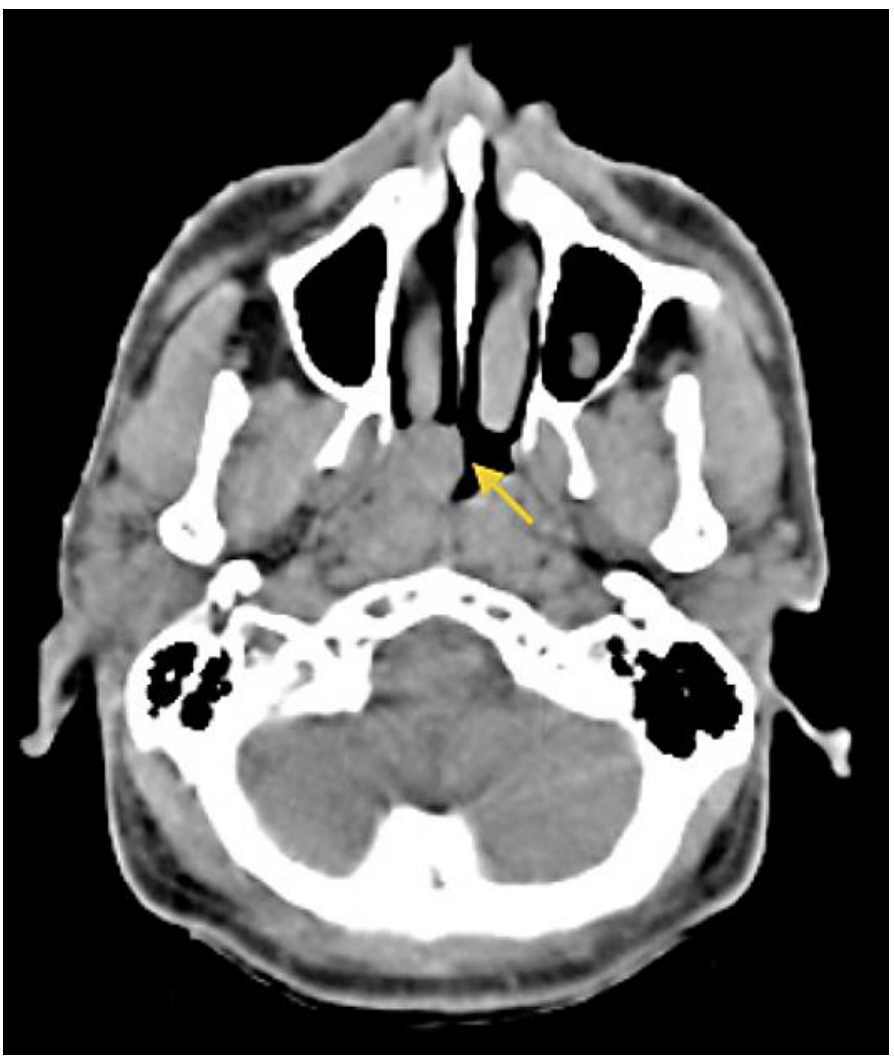

Fig. 1. Axial image demonstrating a mass arising from the right nasopharynx with extension into the upper nasopharynx, obstructing the right nasal passage. 


\section{Case Reports in Oncology}

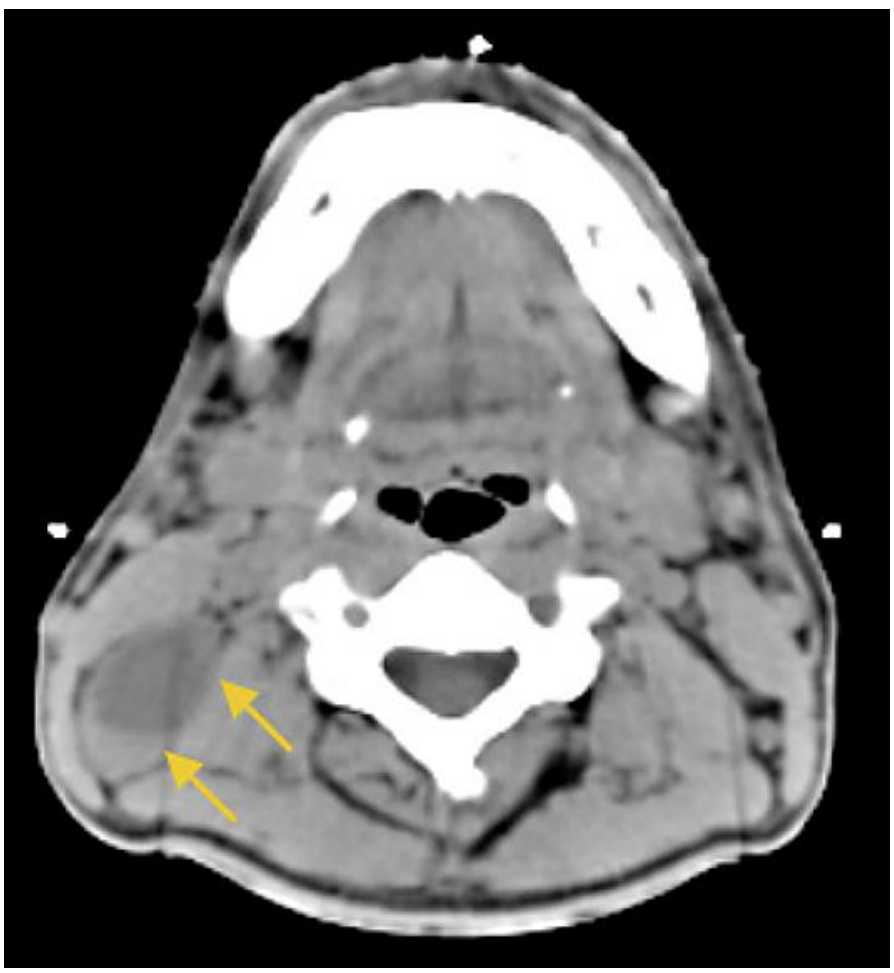

Fig. 2. Axial image demonstrating a hypodense area deep to the right sternocleidomastoid muscle consistent with a level IIB lymph node involvement.

Frequency $(\mathrm{Hz})$

$\begin{array}{lllllllll}250 & 500 & 1000 & 1500 & 2000 & 3000 & 4000 & 6000 & 8000\end{array}$
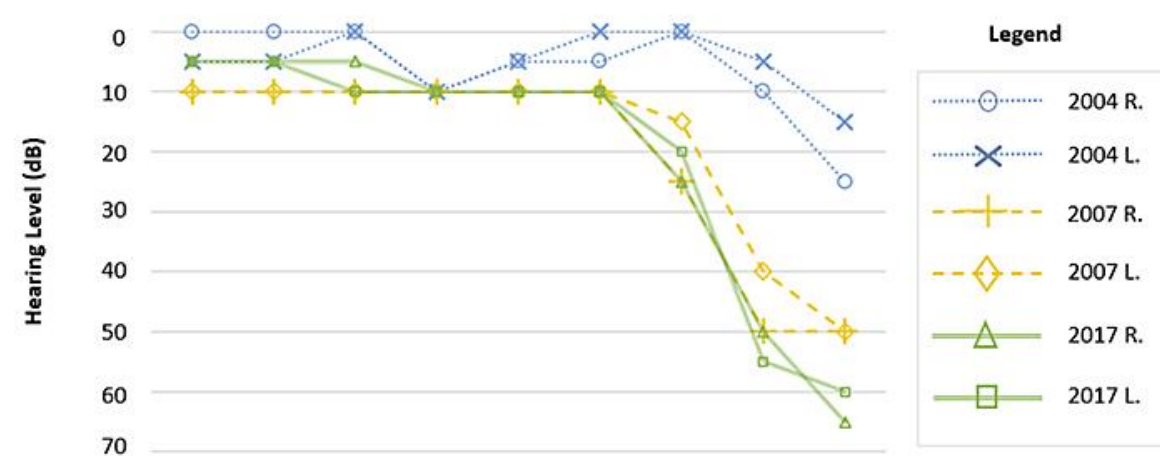

Fig. 3. Series of pure tone air conduction thresholds. 


\section{Case Reports in Oncology}

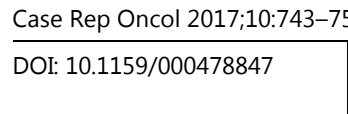

(C) 2017 The Author(s). Published by S. Karger AG, Basel www.karger.com/cro

Lee et al.: Long-Term Progression of SNHL and Tinnitus after Combined

Intensity-Modulated Radiation Therapy and Cisplatin-Based Chemotherapy for NPC

Table 1. Hearing threshold increase between hearing tests

\begin{tabular}{llrrrrrrrr}
\hline $\begin{array}{l}\text { Time } \\
\text { period }\end{array}$ & Ear & $250 \mathrm{~Hz}$ & $500 \mathrm{~Hz}$ & $1,000 \mathrm{~Hz}$ & $2,000 \mathrm{~Hz}$ & $3,000 \mathrm{~Hz}$ & $4,000 \mathrm{~Hz}$ & $6,000 \mathrm{~Hz}$ & $8,000 \mathrm{~Hz}$ \\
\hline 2004 & Right & 10 & 10 & 10 & 5 & 5 & 25 & 40 & 25 \\
to 2007 & Left & 5 & 5 & 10 & 5 & 10 & 15 & 35 & 35 \\
\hline $\begin{array}{l}2007 \\
\text { to } 2017\end{array}$ & Right & -5 & -5 & -5 & 0 & 0 & 0 & 0 & 15 \\
\hline
\end{tabular}

Table 2. Hearing threshold levels for various fractions of otologically normal males in their 30 s and 40 s [11]

\begin{tabular}{llrrrrrrrr}
\hline Age & Fractions, $\%$ & $250 \mathrm{~Hz}$ & $500 \mathrm{~Hz}$ & $1,000 \mathrm{~Hz}$ & $2,000 \mathrm{~Hz}$ & $3,000 \mathrm{~Hz}$ & $4,000 \mathrm{~Hz}$ & $6,000 \mathrm{~Hz}$ & $8,000 \mathrm{~Hz}$ \\
\hline $30 \mathrm{~s}$ & 10 & -4 & -5 & -7 & -8 & -8 & -7 & -3 & -6 \\
& 50 & 3 & 2 & 0 & 0 & 1 & 2 & 8 & 6 \\
& 90 & 12 & 10 & 8 & 10 & 12 & 14 & 21 & 22 \\
\hline $40 \mathrm{~s}$ & 10 & -3 & -4 & -6 & -7 & -6 & -4 & 0 & -2 \\
& 50 & 5 & 3 & 1 & 2 & 5 & 8 & 14 & 14 \\
& 90 & 14 & 12 & 10 & 14 & 18 & 23 & 31 & 33 \\
\hline Increase & 10 & 1 & 1 & 1 & 1 & 2 & 3 & 3 & 4 \\
from 30s & 50 & 2 & 1 & 1 & 2 & 4 & 6 & 6 \\
to 40s & 90 & 2 & 2 & 2 & 4 & 6 & 9 & 10 & 11 \\
\hline
\end{tabular}

